\title{
Spectroscopic characterization of phases formed by high-dose carbon ion implantation in silicon
}

\author{
C. Serre, A. Pérez-Rodriguez, a) A. Romano-Rodríguez, and J. R. Morante \\ LCMM, Departament de Fisica Aplicada i Electronica, Universitat de Barcelona, Avinguda Diagonal \\ 645-647, 08028 Barcelona, Spain \\ R. Kögler and W. Skorupa \\ Forschungszentrum Rossendorf e.V., Institut für Ionenstrahlphysik und Materialforschung, Postfach 510119 , \\ D-01314 Dresden, Germany
}

(Received 19 August 1994; accepted for publication 3 December 1994)

\begin{abstract}
High-dose carbon-ion-implanted Si samples have been analyzed by infrared spectroscopy, Raman scattering, and $\mathrm{x}$-ray photoelectron spectroscopy (XPS) correlated with transmission electron microscopy. Samples were implanted at room temperature and $500^{\circ} \mathrm{C}$ with doses between $10^{17}$ and $10^{18} \mathrm{C}^{+} / \mathrm{cm}^{2}$. Some of the samples were implanted at room temperature with the surface covered by a capping oxide layer. Implanting at room temperature leads to the formation of a surface carbon-rich amorphous layer, in addition to the buried implanted layer. The dependence of this layer on the capping oxide suggests this layer to be determined by carbon migration toward the surface, rather than surface contamination. Implanting at $500^{\circ} \mathrm{C}$, no carbon-rich surface layer is observed and the $\mathrm{SiC}$ buried layer is formed by crystalline $\beta$-SiC precipitates aligned with the $\mathrm{Si}$ matrix. The concentration of $\mathrm{SiC}$ in this region as measured by XPS is higher than for the room-temperature implantation. (C) 1995 American Institute of Physics.
\end{abstract}

\section{INTRODUCTION}

High-dose ion implantation has been extensively used for the synthesis of buried compound layers. In Si technology, $\mathrm{O}$ and $\mathrm{N}$ are successfully implanted to form silicon-oninsulator (SOI) structures, and different metals have been implanted to form metallic or semiconductor silicides. In this framework, the implantation of $\mathrm{C}$ in $\mathrm{Si}$ to form $\mathrm{SiC}$ layers is receiving strong interest, due to the increasing interesting in this material for UV sensor and high-temperature electronic devices. ${ }^{1}$

Different authors have reported the synthesis of SiC by high-dose ion implantation and anneal processes. ${ }^{2-5}$ According to these works, implanting at room temperature leads to the formation of amorphous $\mathrm{SiC}$ and an annealing at temperatures of $850-900^{\circ} \mathrm{C}$ is needed to crystallize the SiC. Moreover, implanting at high temperatures allows the direct synthesis of crystalline $\beta$-SiC. For implantation temperatures higher than $850^{\circ} \mathrm{C}$, high-crystalline-quality $\beta$-SiC is obtained, with $\mathrm{SiC}$ grains in epitaxial relationship with the $\mathrm{Si}$ matrix. 3,5

In this work, the spectroscopic characterization of highdose carbon-ion-implanted silicon samples has been performed for different implantation and annealing conditions. The aim of the work is to deepen the knowledge of the phases formed by high-dose ion implantation, as well as their dependence on the implantation conditions and annealing treatments. This knowledge is critical for the optimization of the technological parameters to achieve the synthesis of high-quality single-crystal $\mathrm{SiC}$ layers in $\mathrm{Si}$. According to previous works, conditions that have been considered are the implantation dose and temperature, as well as the presence of a capping $\mathrm{SiO}_{2}$ layer on the sample surface during

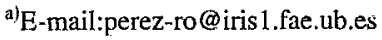

implantation. ${ }^{2-6}$ The presence of this layer has been proposed to reduce contamination and channeling effects, as well as to protect the surface from sputtering. Moreover, the analysis of SOI structures formed by high-dose oxygen ion implantation has shown a strong dependence of the structure and density of defects of the samples on the presence of a capping layer during the implantation process. ${ }^{6}$

The analysis of the implanted and annealed samples has been performed by Fourier transform infrared spectroscopy (FTIR), Raman scattering, and x-ray photoelectron spectroscopy (XPS), in correlation with planar-view and crosssection transmission electron microscopy (TEM).

\section{EXPERIMENTAL DETAILS}

(001) B-doped device-grade Czochralski Si wafers $(16-24 \Omega \mathrm{cm})$ were implanted at room temperature and $500^{\circ} \mathrm{C}$ with different doses and energies, as follows.

(a) Implantations performed with the sample at room temperature: The implantation energy was $150 \mathrm{keV}$, and implanted doses were $10^{17}$ and $10^{18} \mathrm{C}^{+} / \mathrm{cm}^{2}$. Before implantation, half of the wafers were covered with a 40 $\mathrm{nm} \mathrm{SiO}_{2}$ capping layer. These samples are labeled RT.

(b) Implantations performed with the sample at $500^{\circ} \mathrm{C}$ : The implantation energy was $300 \mathrm{keV}$, and the implanted doses were $10^{17}$ and $5 \times 10^{17} \mathrm{C}^{+} / \mathrm{cm}^{2}$. These samples are labeled HT.

Implantations were performed at $7^{\circ}$ to minimize channeling effects. In these conditions, the projected ranges and straggles of the implanted ions are 386 and $81 \mathrm{~nm}$ at $150 \mathrm{keV}$ and 677 and $106 \mathrm{~nm}$ at $300 \mathrm{keV}$, respectively, as calculated with the Monte Carlo simulation code TRIM $90{ }^{7}$ The use of these two energies for the implantations performed at different temperatures was related to the characteristics of the 
implanter machines: In each case, the energy was determined by the value for which an optimum implantation current is obtained. For the RT implantations, an implanter machine with a large beam area was used, which allowed implantation with a beam current density low enough to avoid selfheating, while keeping a reasonable implantation time. For HT implantations, a machine with heating capabilities was required.

Samples from the wafers were annealed at different temperatures (up to $1150^{\circ} \mathrm{C}$ ) in a conventional furnace during $10 \mathrm{~h}$ in nitrogen ambient. Before annealing, the capping or native surface oxide layer was removed in HF and a PECVD $\mathrm{SiO}_{2}$ layer ( $1 \mu \mathrm{m}$ thick) was deposited.

FTIR transmission measurements were performed with a BOMEM DA3 spectrometer. The spectra were measured in vacuum at room temperature, using normal incidence and with a spectral resolution of $1 \mathrm{~cm}^{-1}$. Absorption spectra from the implanted samples were extracted by using the reference spectra from wafers that were not implanted nor annealed, with the same oxide capping layer when necessary. Raman scattering measurements were done in backscattering geometry with a Jobin-Yvon T64000 spectrometer coupled with an Olympus metallographic microscope. To analyze the different Si-Si-, Si-C-, and C-C-related modes, the spectra were measured in the broad spectral region between 100 and 1700 $\mathrm{cm}^{-1}$. Excitation was provided by an $\mathrm{Ar}^{+}$laser operating at a wavelength of $514 \mathrm{~nm}$. For this excitation wavelength, the penetration depth of scattered light in single-crystal $\mathrm{Si}$ is estimated to be of about $0.8 \mu \mathrm{m}$; however, for highly defective material there is a significant reduction of this penetration depth, due to the increase in light absorption. Moreover, the excitation power has been kept below $0.3 \mathrm{~kW} / \mathrm{cm}^{2}$ to avoid thermal effects in the Raman spectra. All the spectra are compared with those measured under the same conditions from a nonprocessed $\mathrm{Si}$ wafer.

XPS measurements were carried out with a PerkinElmer PHI 5500 spectrometer with $\mathrm{A} 1 K \alpha$ radiation. To investigate the distribution of the different phases formed in the implanted samples, XPS measurements were performed after sputtering the samples to different thicknesses with an $\mathrm{Ar}^{+}$-ion beam at $3 \mathrm{keV}$. For the measuring conditions used, the full width at half-maximum (FWHM) of the $\mathrm{Ag} 3 d_{5 / 2}$ line was of $1 \mathrm{eV}$. Finally, samples from the different wafers were analyzed by planar-view and cross-section TEM using either a Hitachi H-800-NA microscope operated at $200 \mathrm{keV}$ or a Philips CM30 SuperTwin microscope, uperated at 300 $\mathrm{keV}$.

\section{RESULTS}

\section{A. FTIR analysis}

Figure 1 shows the infrared absorption spectra from different implanted and annealed samples. As can be seen, all the measured spectra are characterized by the absorption peak related to the $\mathrm{Si}-\mathrm{C}$ bond. For the RT sample implanted at the higher dose $\left(10^{18} \mathrm{~cm}^{-2}\right)$, the spectrum shows a broad band centered at about $700 \mathrm{~cm}^{-1}$. This is related to the presence of an amorphous SiC network in the implanted layer. ${ }^{8,9}$ Annealing the sample the spectra become sharper and shift

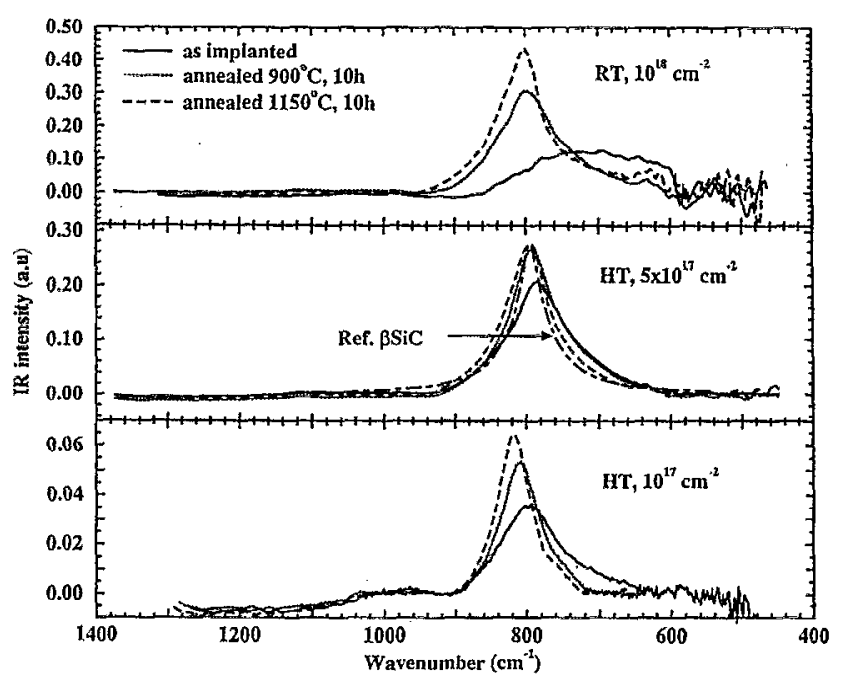

FIG. 1. Infrared absorbance spectra from RT samples (implantation dose $10^{18} \mathrm{~cm}^{-2}$ ) and HT samples (implantation doses $5 \times 10^{17}$ and $10^{17} \mathrm{~cm}^{-2}$ ). A reference crystalline $\beta$-SiC spectrum simulated according to Ref. 10 is also shown.

toward higher wave numbers, approaching the values reported for crystalline $\mathrm{SiC}$. This indicates the crystallization of $\mathrm{SiC}$ during annealing.

For the HT samples implanted at the higher dose $\left(5 \times 10^{17} \mathrm{~cm}^{-2}\right)$, the spectrum from the as-implanted sample is rather similar to that of the annealed ones: The SiC peak appears at a wave number of $785 \mathrm{~cm}^{-1}$ with a FWHM of about $94 \mathrm{~cm}^{-1}$. These values suggest the formation of crystalline $\mathrm{SiC}$ already after implantation at $500^{\circ} \mathrm{C}$. After annealing, the peak becomes sharper and approaches the value of $794 \mathrm{~cm}^{-1}$ of the TO phonon of $\beta-S i C$. This can be seen in Fig. 1, where the reference spectrum from a single-crystal $\beta$-SiC is also shown. ${ }^{10}$ These changes are determined by the improvement of crystalline quality with annealing.

The spectra measured on the samples implanted at lower doses are similar; however, the final position of the $\mathrm{SiC} \mathrm{ab-}$ sorption peak after annealing at $1150^{\circ} \mathrm{C}$ appears at a higher wave number, about $822 \mathrm{~cm}^{-1}$. According to previous data ${ }^{11}$ this could be determined by the formation of $\mathrm{SiC}$ precipitates in the Si matrix rather than a $\mathrm{SiC}$ layer.

\section{B. Raman scattering}

The formation of an amorphous phase after RT implantation is clearly deduced from Raman measurements. In Fig. 2 are plotted the spectra measured in the samples implanted at the higher doses. A similar behavior is observed for the lower-implantation doses.

The Raman spectra of the RT samples implanted without a capping layer [Fig. 2(a)] show the bands characteristic of amorphous $\mathrm{Si}$, superimposed on the attenuated first-order peak from crystalline $\mathrm{Si}\left(c-\mathrm{Si}\right.$, about $\left.520 \mathrm{~cm}^{-1}\right)$. The secondorder peaks of crystalline $\mathrm{Si}$ are not visible, due to the amorphization of $\mathrm{Si}$ in the scattering volume. In addition, a broad band in the $1350-1580 \mathrm{~cm}^{-1}$ region appears, corresponding to $\mathrm{C}-\mathrm{C}$ bonds. This indicates the amorphization of the implanted samples for the RT implantation, with the presence 


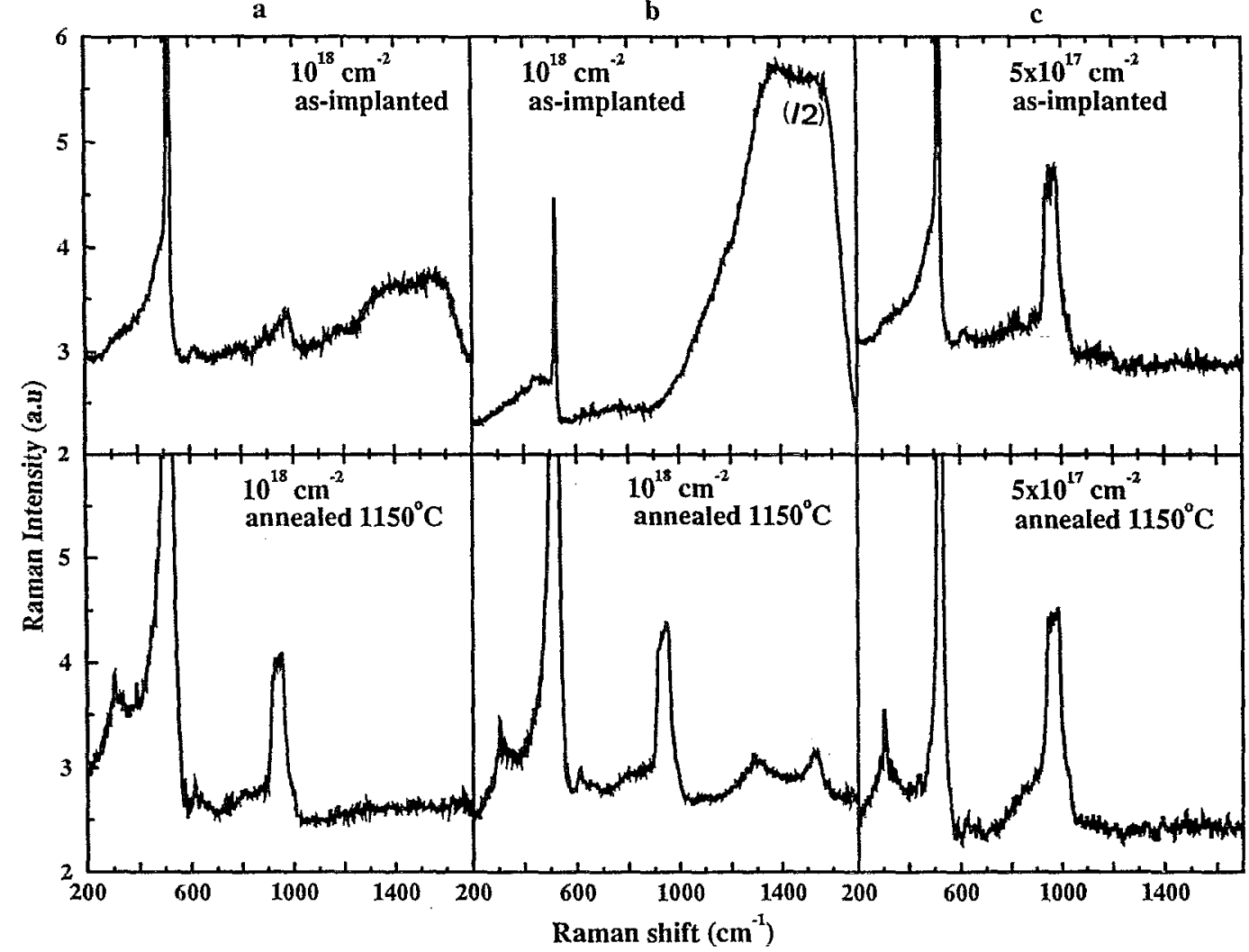

FIG. 2. Raman scattering spectra from samples: (a) RT (dose $10^{18} \mathrm{~cm}^{-2}$ ); (b) RT implanted with capping oxide (dose $10^{18} \mathrm{~cm}^{-2}$ ); and (c) HT (dose $5 \times 10^{17}$ $\mathrm{cm}^{-2}$ ). Arbitrary units of $Y$ scaled from spectra (b) are twice those from spectra (a) and (c).

of $\mathrm{Si}-\mathrm{Si}$ and $\mathrm{C}-\mathrm{C}$ bonds. In fact, similar spectra have been measured in amorphous $\mathrm{SiC}$ layers with different compositions obtained by glow discharge decomposition of a silane and methane mixture diluted by helium. ${ }^{12}$

After annealing, the amorphous contribution in the spectra disappears and the first- and second-order peaks from $c$-Si are restored. This can be seen in the spectrum plotted in Fig. 2(a), which clearly shows the peak at $302 \mathrm{~cm}^{-1}$ $[2 \mathrm{TA}(\mathrm{X})]$ and the second-order band at the $900-1000 \mathrm{~cm}^{-1}$ region (associated with overtones and combinations involving optical phonons), ${ }^{13}$ in addition to the first-order line at $520 \mathrm{~cm}^{-1}$. Moreover, no peaks directly related to $\mathrm{Si}-\mathrm{C}$ or $\mathrm{C}-\mathrm{C}$ bonds are observed. This might be due to the fact that the TO peak from crystalline $\beta-\mathrm{SiC}$ at $796 \mathrm{~cm}^{-1}$ is forbidden, as measurements are made in backscattering geometry on a (001) surface, and assuming $\beta$-SiC to be aligned with the Si matrix. Moreover, the LO peak at $972 \mathrm{~cm}^{-1}$ is superimposed to the broad band at $900-1000 \mathrm{~cm}^{-1}$ from $c$-Si.

The main feature observed in the sample implanted through a capping layer is a strong enhancement of the $\mathrm{C}-\mathrm{C}$ bond contribution [Fig. 2(b)]; however, this component disappeared after removing the capping layer by dipping the sample in HF. The strong intensity of this component indicates the formation of a carbon rich amorphous layer, likely located at the $\mathrm{SiO}_{2}-\mathrm{Si}$ interface region, which is removed by HF etching.

On the other hand, no amorphous signal is detected in the Raman spectra from the HT as-implanted samples [Fig. 2(c)], and only the first- and second-order peaks of $c$-Si are observed. The asymmetric shape and shift of the first-order Raman peak and the lower intensity of the second-order peaks in relation to the spectrum from nonimplanted $\mathrm{Si}$ indicate the presence of a high density of structural defects. After annealing the spectra become very similar to those measured in a nonimplanted Si wafer, due to the improvement of crystalline quality, although the first-order $c$-Si peak shows a small residual shift of about $0.15 \mathrm{~cm}^{-1}$ toward the lowfrequency side. This could be determined by the presence of both residual structural defects in the Si matrix or strain induced by the implantation process.

\section{XPS analysis}

The distribution of the implanted ions and the different species in the samples has been investigated by measuring the $\operatorname{Ar} 2 p, \mathrm{C} 1 s$, Si $2 p$, and $\mathrm{O} 1 s$ spectra in samples sputtered with the $\mathrm{Ar}^{+}$beam at different depths.

First of all, we have observed that there is no oxygen contribution, except at the surface, due to the presence of the native surface oxide and surface contamination. Moreover, the Ar spectra measured at different depths have always the same shape and position. This indicates that: (i) no charge effects take place during the XPS measurements in the implanted layers, and (ii) there are no changes in the position of the Fermi level as the measured depth increases. According to this, changes observed in the spectra have to be assigned 
0

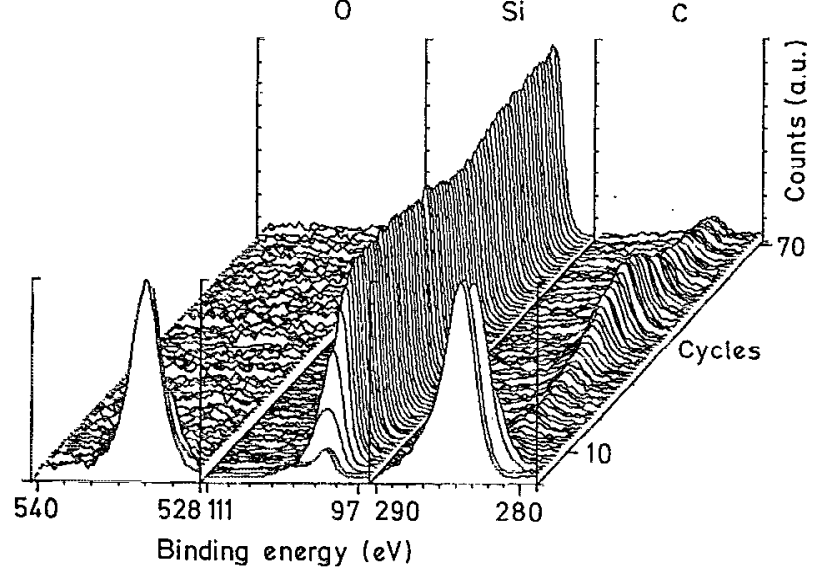

FIG. 3. O $1 s$, Si $2 p$, and C $1 s$ XPS spectra measured at different depths in the RT sample implanted with the dose of $10^{18}$ ions $/ \mathrm{cm}^{2}$.

to changes of the chemical environment. This has been observed in all the measured samples.

From these measurements, the carbon concentration at the implanted peak has been estimated to be of about $2.3 \times 10^{22}$ and $3 \times 10^{22} \mathrm{~cm}^{-3}$ for the RT and HT samples implanted at the highest doses, respectively.

Figure 3 shows the spectra measured in the RT sample implanted at the higher dose. The $\mathrm{C} 1 s$ peaks observed in the two first measuring cycles correspond to surface contamination. After this, there are two regions with a significant carbon content: a thin region just below the surface and the buried region corresponding to the implantation peak. In the subsurface region, the intensity of the peak decreases with depth. Moreover, the peak appears at values above $284 \mathrm{eV}$. Increasing the depth, the peak shifts toward $283 \mathrm{eV}$, becoming similar to the peak measured in the buried region. According to the data in the literature ${ }^{14-16}$ this indicates the presence of a $\mathrm{C}$-rich layer in the surface region, with a dominant contribution of $\mathrm{C}-\mathrm{C}$ bonds, and correlates with the features observed in the Raman spectra. As the depth increases, the carbon content decreases and the peak tends to the value corresponding to $\mathrm{SiC}$. In the buried layer only the $\mathrm{SiC}$ contribution is observed in the peak.

In the case of the samples implanted at $500{ }^{\circ} \mathrm{C}$, no such C-rich surface layer is observed, and only the $\mathrm{SiC}$ contribution is found in the buried region.

In agreement with $\mathrm{C} 1 s$ spectra, the Si $2 p$ spectra after deconvolution show the presence of two contributions: a peak at $99.4 \mathrm{eV}$ (corresponding to the Si phase) and a second peak at about $100.1 \mathrm{eV}$, which is assigned to the $\mathrm{SiC}$ phase. ${ }^{14-16}$ The fitting of the spectra with these contributions has allowed us to determine the in depth distribution of the percentage of $\mathrm{Si}$ atoms in both $\mathrm{Si}$ and $\mathrm{SiC}$ phases. In Fig. 4 these percentages are plotted for the samples implanted at the higher doses, as measured by XPS. For the RT sample the $\mathrm{SiC}$ phase shows a surface maximum (with about $80 \%$ of the $\mathrm{Si}$ atoms bonded to $\mathrm{C}$ ), corresponding to the surface $\mathrm{C}$-rich $\mathrm{SiC}$ region. At the implantation peak, about $47 \%$ of the $\mathrm{Si}$ atoms is bonded to $\mathrm{SiC}$, and $53 \%$ is bonded to $\mathrm{Si}$. After annealing, the surface peak disappears and the percentage of $\mathrm{Si}$ atoms in the $\mathrm{SiC}$ phase slightly increases to about $52 \%$, the remaining being $\mathrm{Si}$ atoms bonded to $\mathrm{Si}$. According to these data, in spite of the high implanted dose $\left(10^{18} \mathrm{~cm}^{-2}\right)$, a stoichiometric continuous buried layer is not achieved.

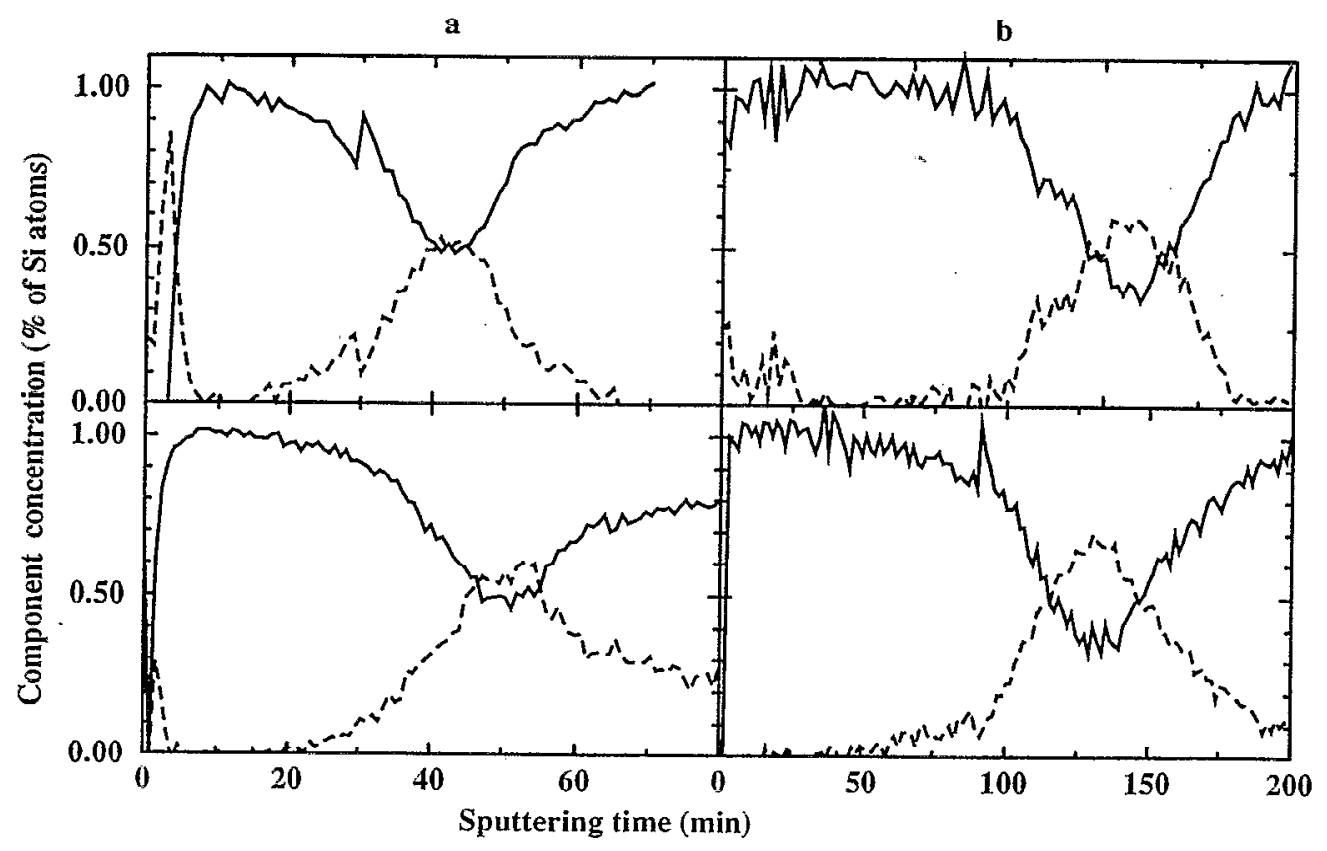

FIG. 4. Percentage of $\mathrm{Si}$ atoms in $\mathrm{Si}$ (solid line) and $\mathrm{SiC}$ (dotted line) phase as measured by XPS vs sputter time from samples: (a) RT implanted with a dose of $10^{18}$ ions $/ \mathrm{cm}^{2}$ and (b) HT implanted with a dose of $5 \times 10^{17}$ ions $/ \mathrm{cm}^{2}$. Etching rates were $6 \mathrm{~nm} / \mathrm{min}$ (samples as implanted) and $4.9 \mathrm{~nm} / \mathrm{min}$ (samples annealed). Carbon concentration at the implanted peak is estimated to be about $2.3 \times 10^{22}$ and $3 \times 10^{22} \mathrm{~cm}^{-3}$ for the RT and HT samples, respectively. 
TABLE I. Peak position and FWHM (in $\mathrm{eV}$ ) of the two contributions appearing in the XPS spectra from the RT and HT samples implanted at the highest doses (as implanted).

\begin{tabular}{cccc}
\hline \hline Sample & Peak & FWHM & Assigned to \\
\hline RT & 99.4 & 2.03 & $\mathrm{Si}$ \\
& 100.05 & 2.40 & $\mathrm{SiC}$ \\
$\mathrm{HT}$ & 99.4 & 2.03 & $\mathrm{Si}$ \\
& 100.2 & 2.02 & $\mathrm{SiC}$ \\
\hline
\end{tabular}

The comparison between the spectra from the asimplanted RT and HT samples indicates that the $\mathrm{SiC}$ contribution in the RT sample appears at a slightly lower energy and with a higher FWHM than in the HT one. This can be seen in Table I, where the peak position and FWHM of both contributions are indicated for these samples. This behavior can be explained by taking into account the tetrahedron model valid for amorphous $\mathrm{SiC},{ }^{16,17}$ since FTIR shows an amorphous contribution. This model assumes a possible contribution of the five tetrahedral bonding components $\mathrm{Si}_{-}-\mathrm{Si}_{4-n} \mathrm{C}_{n}$ with $n=0-4$. The fitting of the spectra according to the data of Takeshita and co-workers ${ }^{16}$ shows some contribution of the $\mathrm{Si}-\mathrm{Si}_{3} \mathrm{C}$ configuration, in addition to the $\mathrm{Si}_{-} \mathrm{Si}_{4}$ and $\mathrm{Si}_{-} \mathrm{C}_{4}$ ones in the RT as-implanted sample, as is shown in Fig. 5. According to Mui and Smith, ${ }^{17}$ the two tetrahedra with the highest probability of occurrence in amorphous phases are always consecutive ones; therefore, these data suggest the contribution in the buried layer of two different phases: (i) a C-rich $\mathrm{Si}$ amorphous phase and (ii) a stoichiometric $\mathrm{SiC}$ phase. After annealing, recrystallization of $\mathrm{SiC}$ occurs-as indicated by FTIR-and only $\mathrm{Si}_{-}-\mathrm{Si}_{4}$ and $\mathrm{Si}-\mathrm{C}_{4}$ configurations contribute to the spectra.

Implanting at $500^{\circ} \mathrm{C}$, no C-rich surface region is observed at all. In this case the shape and position of the $\mathrm{Si}$ and $\mathrm{SiC}$ contributions to the Si $2 p$ spectra do not change with annealing. This correlates with the FTIR and Raman data, which suggest the formation of crystalline $\mathrm{SiC}$ already in the

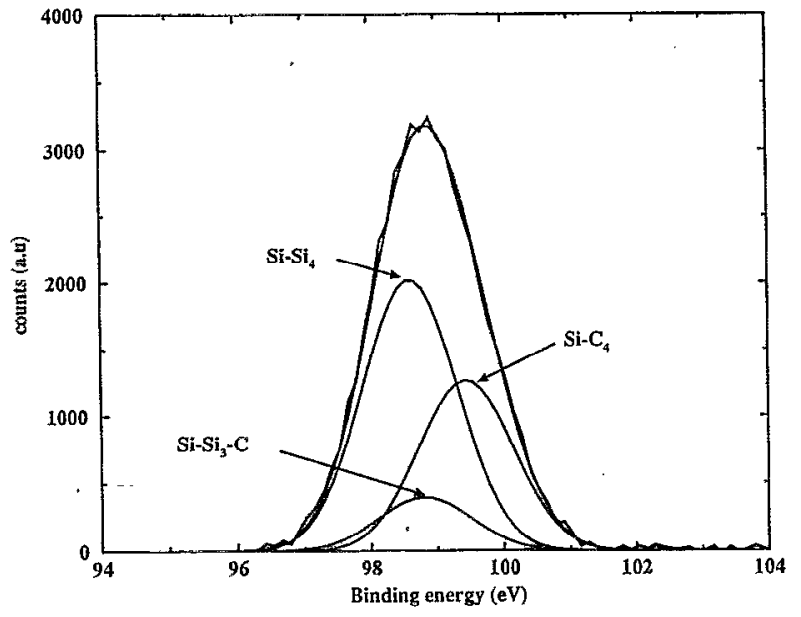

FIG. 5. XPS spectrum measured in the buried layer from the RT sample implanted with $10^{18}$ ions $/ \mathrm{cm}^{2}$, and theoretical simulation showing the $\mathrm{Si}_{-} \mathrm{Si}_{4}$, $\mathrm{Si}-\mathrm{Si}_{3} \mathrm{C}$, and $\mathrm{Si}-\mathrm{C}_{4}$, contributions.

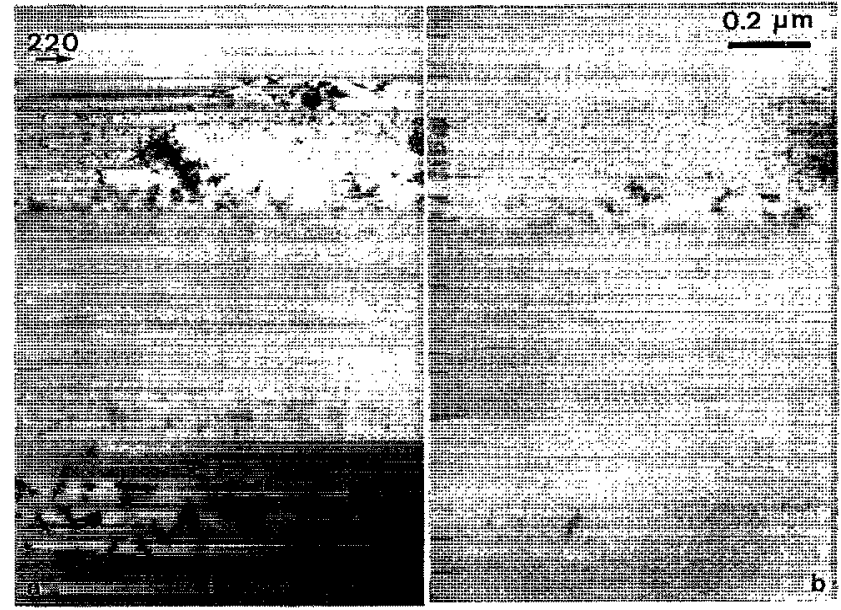

FIG. 6. Cross-section TEM images of the HT samples (dose $5 \times 10^{17} \mathrm{~cm}^{-2}$ ): (a) as implanted and (b) annealed at $1150^{\circ} \mathrm{C}$ for $10 \mathrm{~h}$.

as-implanted samples. Moreover, the implantation at $500^{\circ} \mathrm{C}$ appears as more effective for the formation of the $\mathrm{SiC}$ buried layer. Higher $\mathrm{SiC}$-to-Si ratios are obtained, in spite of the lower implantation dose $\left(5 \times 10^{17} \mathrm{~cm}^{-2}\right)$, although a continuous buried SiC layer is still not formed. As is shown in Fig. 4 , for the as-implanted sample about $63 \%$ of the Si atoms are in the $\mathrm{SiC}$ phase at the implantation peak. After annealing, this percentage increases to about $68 \%$.

\section{TEM observations}

Figure 6 corresponds to cross-section images of the HT samples (dose $5 \times 10^{17} \mathrm{~cm}^{-2}$ ) (a) as implanted and (b) annealed. The first region that can be observed in the asimplanted sample is a silicon surface layer with an increasing density of spherical defects, probably $\beta$-SiC precipitates, which extends to a depth of about $350 \mathrm{~nm}$. Extended defects are observed at the right-hand-side part of the figure that, from planar-view results, form a networklike distribution along [110] directions in the subsurface region and whose nature has not yet been determined. Next a buried layer appears, with a thickness of $500 \mathrm{~nm}$, which corresponds to the implantation peak. Electron-diffraction diagrams from this region show the presence of extra spots superimposed on the ones of silicon, which are identified as being $\beta$-SiC. They are present in the form of precipitates and are perfectly oriented to the silicon matrix, as obtained from diffraction diagrams and by the presence of moire fringes, observed at higher magnifications. Finally, below the buried layer, \{113\}-type defects are observed in the $\mathrm{Si}$ substrate in the as-implanted sample. They are separated from the buried layer by a layer denuded of defects. These defects are related to a selfinterstitial oversaturation, and have also been observed below the buried layer synthesized for SOI structures formed by oxygen and/or nitrogen implantation. ${ }^{18}$

After annealing the samples at the highest temperature [Fig. 6(b)] little changes occur, the main ones being the removal of the extended defects above and below the buried layer and the extension of the small precipitates further below the buried layer. 


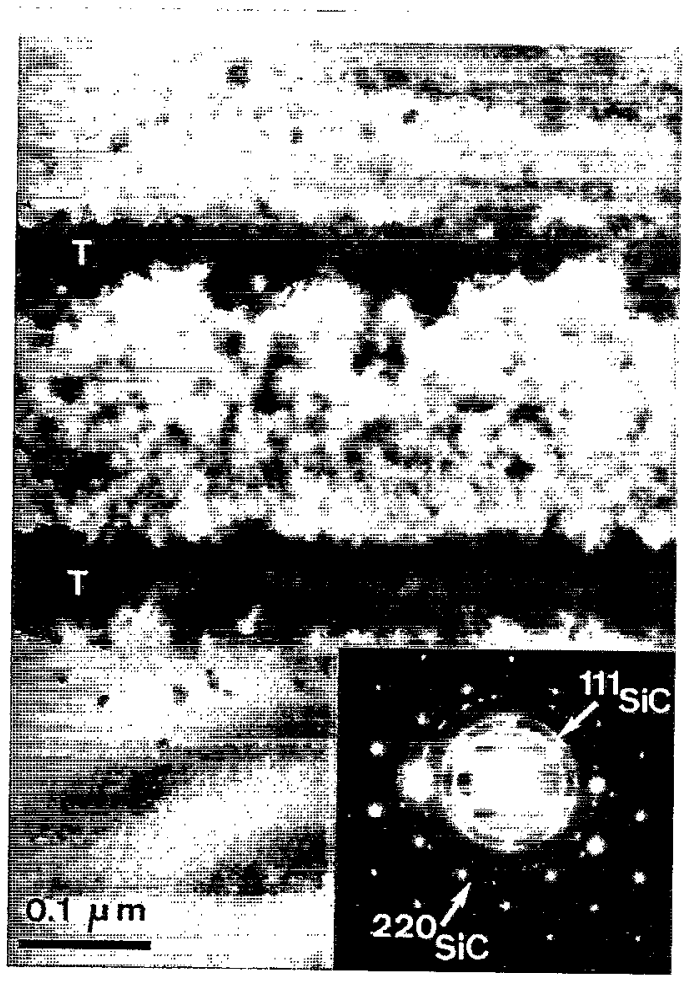

FIG. 7. Cross-section TEM image of the RT sample (dose $1 \times 10^{18} \mathrm{~cm}^{-2}$ ) annealed at $1150^{\circ} \mathrm{C}$ for $10 \mathrm{~h}$. The inset shows a diffraction diagram of the top silicon and buried polycrystalline layers, revealing the presence of randomly oriented $\beta$-SiC in the buried layer.

A cross section of the RT sample implanted with a capping oxide layer (dose $10^{18} \mathrm{~cm}^{-2}$ ) and annealed is shown in Fig. 7. The first remark is the small surface rugosity. Down to a thickness of $150 \mathrm{~nm}$ the layer is silicon with precipitates, mostly spherical or octahedral in shape. Transmission electron diffraction diagrams did not reveal any crystallinity from these precipitates. The second layer is a 190-nm-thick buried polycrystalline layer, limited on the top and bottom by regions with twins: The upper one is about $40 \mathrm{~nm}$ thick, while the lower is $70 \mathrm{~nm}$ thick. Both regions are formed after the annealing from the recrystallization of the amorphous layer formed during the RT implantation. The inset in the figure is a diffraction diagram from the top silicon (spots) and from the buried layer (rings), and shows the polycrystalline nature of this layer. The presence of polycrystalline $\beta$-SiC, already deduced from FTIR results, is confirmed by the presence of some extra rings. In contrast with HT samples, in this case crystalline $\mathrm{SiC}$ grains are randomly oriented. Finally, below the lower twinned layer some small precipitates are also visible, probably being amorphous $\mathrm{SiC}$.

\section{DISCUSSION}

The Raman scattering and XPS measurements point out the existence of two mechanisms during the implantation process: (a) the formation of a SiC phase in the buried implantation peak region, and (b) a migration of $C$ toward the surface, similar to a surface gettering mechanism. At RT both mechanisms are competitive, and take place. In this case, the phases induced by the high-dose implantation are amor- phous, according to the Raman scattering and FTIR data. The coexistence of both mechanisms leads to the formation of a C-rich surface layer, in addition to the buried one. This layer is characterized by the presence of both amorphous carbon and SiC phases. So, both XPS and Raman spectra show the contribution of these two phases. At the surface, the $\mathrm{C} 1 s$ XPS spectrum appears at the position corresponding to carbon. Increasing in depth, the signal moves toward the SiC one. This indicates a change of the dominant carbon-related phase, from amorphous carbon to amorphous $\mathrm{SiC}$. In front of this, in the buried layer two phases appear: C-rich amorphous $\mathrm{Si}$ and amorphous stoichiometric SiC.

The comparison between the Raman and XPS spectra from samples implanted with and without the capping oxide suggests that part of carbon migrating toward the surface is able to go away from the sample if the surface is free. This would explain the similar carbon in-depth distribution in the samples implanted at room temperature with and without the capping oxide - as observed by XPS - and the high intensity of the C-C contribution in the Raman spectra from samples implanted with a capping oxide layer. When the sample surface is covered by the capping layer, carbon cannot go away from the sample, and likely accumulates in the $\mathrm{SiO}_{2} / \mathrm{Si}$ interface region, forming an amorphous $\mathrm{C}$-rich layer.

Increasing the implantation temperature, mechanism (a) is enhanced in relation to mechanism (b). Implanting at $500^{\circ} \mathrm{C}$, no carbon signal is detected by XPS spectroscopy in the surface region. At this temperature the synthesized phase is $\beta-\mathrm{SiC}$, the $\mathrm{SiC}$ precipitates being aligned with the Si matrix. According to this, the higher implantation temperature leads to a new $\mathrm{SiC}$ formation mechanism, the $\mathrm{SiC}$ grains being epitaxially related to the Si lattice, and this mechanism is far more favorable than carbon migration toward the surface:

On the other hand, the differences in the implantation energy could also have some influence in the inhibition of mechanism (b) in the HT samples. In this case, the higher implantation energy determines a higher penetration of the ions and, hence, a lower role of the surface is to be expected; however, previous observation of samples implanted at 300 $\mathrm{keV}$ at $\mathrm{RT}$ and lower doses indicates the occurrence of mechanism (b). According to this, the disappearance of this mechanism in HT samples is determined by the higher implantation temperature. On the other hand, differences of straggling are not expected to play a significant role because of the high doses used. Thus, differences observed between the RT and HT samples are more likely determined by the implantation temperature. The inhibition of carbon migration to the surface observed for HT samples can explain the higher carbon content in the buried layer as measured by XPS, even if the implantation dose was half of the dose implanted at room temperature.

Moreover, the structure obtained is very stable under annealing: For annealing temperatures up to $1150^{\circ} \mathrm{C}$ the only change observed is essentially related to the removal of structural defects, and no carbon distribution or phase changes are observed. This is in contrast with the behavior of the samples implanted at room temperature: Annealing the samples the C-rich surface layer disappears and SiC crystal- 
lizes. However, the crystallization mechanism differs from the direct formation of crystalline $\mathrm{SiC}$ by high-temperature implantation, as in this case the $\mathrm{SiC}$ crystalline grains do not show a preferential orientation in relation to the $\mathrm{Si}$ matrix.

\section{CONCLUSIONS}

The characterization performed shows the dependence of the $\mathrm{SiC}$ formation and structure on the implantation and annealing conditions. Impiantation at room temperature leads to the formation of a surface C-rich layer, in addition to the buried implanted one, which reveals the existence of a carbon migration toward the surface. The behavior observed for samples implanted with a capping layer allows us to rule out surface contamination as the origin of this surface region. Increasing the implantation temperature up to $500^{\circ} \mathrm{C}$ inhibits this mechanism, and $\beta$-SiC crystalline precipitates aligned with the Si matrix are already formed after implantation. In this case, the obtained structures are very stable with annealing treatments, for annealing temperatures up to $1150^{\circ} \mathrm{C}$. These data suggest the interest to implant even at higlies temperatures for the formation of a continuous buried $\mathrm{SiC}$ single-crystalline layer. According to Nejim and co-workers ${ }^{5}$ this would also allow the obtention of high-quality structures with a very low density of structural defects even without annealing.

\section{ACKNOWLEDGMENTS}

RT implantations were performed at AIN (Navarra, Spain). This work was partially funded by Spanish CICYT under Project Ref. MAT92-0351. Part of this work was supported by the Bundes-Ministerium für Forschung und Technologie (Contract No. 03-SK3ROS-5). The authors thank the technical staff at the "Serveis Científico-Tècnics" of the University of Barcelona for their assistance with the spectroscopic measurements and interpretation, and M. Acero and J. Esteve from the "Centro Nacional de Microelectrónica" (CNM-CSIC, Spain) for their support and help in the processing of the samples.

${ }^{1}$ G. Müller, G. Krötz, and E. Niemann, Sensors and Actuators A 43, 259 (1994).

${ }^{2}$ M. Deguchi, M. Kitabatake, T. Hirao, N. Arai, and T. Izumi, Jpn. J. Appl. Phys. 31, 343 (1992).

${ }^{3}$ P. Martin, B. Daudin, M. Dupuy, A. Ermolieff, M. Olivier, A. M. Papon, and G. Rolland, J. Appl. Phys. 67, 2908 (1990).

${ }^{4}$ K. J. Reeson, J. Stoemenos, and P. L. F. Hemment, Thin Solid Films 191, 147 (1990).

${ }^{5}$ A. Nejim, P. L. F. Hemment, and J. Stoemenos, in Proceedings of the 6th International Symposium on SOI Technology and Devices, edited by S. Cristoloveanu, The Electrochemical Society Proceedings Vol. 94-11 (Electrochemical Society, New York, 1994), p. 167.

${ }^{6}$ J. Margail, J. M. Lamure, and A. M. Papon, Mater. Sci. Eng. B 12, 27 (1992).

7J. F. Ziegler, J. P. Biersack, and U. Littmark, The Stopping and Range of Ions in Solids (Pergamon, New York, 1985), Vol. 1.

${ }^{8}$ Y. Katagama, K. Usami, and T. Shimada, Philos. Mag. B 43, 283 (1981).

${ }^{9} \mathrm{~J}$. Ishikawa and H. Tsuji, Nucl. Instrum. Methods Phys. Res. B 74, 118 (1993).

${ }^{10}$ C. J. Mogab, J. Electrochem. Soc. 120, 932 (1973).

${ }^{11} \mathrm{~S}$. Isomae, T. Ishiba, T. Ando, and M. Tamura, J. Appl. Phys. 74, 3815 (1993).

${ }_{12}$ A. Chehaidar, R. Carles, A. Zwick, C. Meunier, B. Cros, and J. Durand, J. Non-Cryst. Solids 169, 37 (1994).

${ }^{13}$ P. A. Temple and C. E. Hathaway, Phys. Rev. B 7, 3685 (1973).

${ }^{14}$ B. Pivac, K. Furic, M. Milun, T. Valla, A. Borghesi, and A. Sassella, J. Appl. Phys. 75, 3586 (1994).

${ }^{15}$ Handbook of X-Ray Photoelectron Spectroscopy, edited by J. Chastain (Perkin-Elmer, MN, 1992).

${ }^{16}$ T. Takeshita, Y. Kurata, and S. Hasegawa, J. Appl. Phys. 71, 5395 (1992).

${ }^{17} \mathrm{~K}$. Mui and F. W. Smith, Phys. Rev. B 35, 8080 (1987).

${ }^{18}$ A. DeVeirman, J. Van Landuyt, and W. Skorupa, Philos. Mag. A 64, 513 (1991). 